\title{
CLIMA ORGANIZACIONAL EN LAS INSTITUCIONES EDUCATIVAS DE SANTA MARTA, COLOMBIA
}

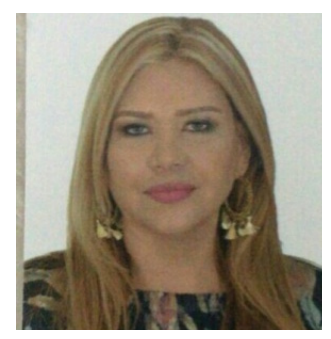

\section{Hincapié Parejo, Nair Farides*}

Institución Educativa Distrital Beatriz Gutiérrez de Vives y del Colegio El Divino Niño. Santa Marta, Colombia. nerita0219@hotmail.com

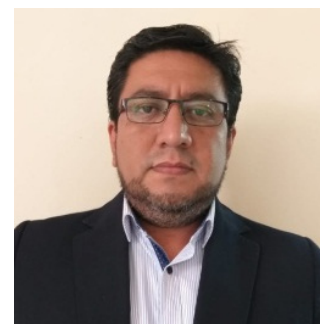

\section{Orellana Orellana, Edison Fernando** \\ Universidad Católica de Cuencas. Ecuador. corellanao@ucacue.edu.ec}

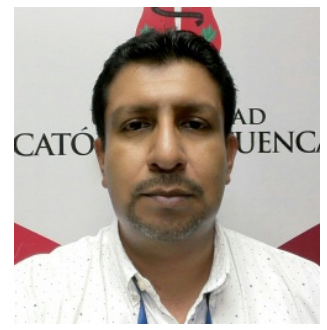

Fecha de recepción: 06/08/2018
Fecha de revisión: 05/09/2018
Fecha de aceptación: 23/10/2018

\section{RESUMEN}

El objetivo del artículo es determinar el clima organizacional en las instituciones escolares de Santa Marta Colombia, bajo los fundamentos teóricos de autores, tales como: Brunet (2008), Robbins y Coulter (2010), Chiavenato, (2006), Daft y Marcic, (2006), Goncalves (2007) entre otros. La investigación fue descriptiva con diseño de campo, transeccional y no experimental. La población estuvo conformada por seis unidades educativas públicas básicas primaria ubicadas en la ciudad de Santa Marta. Las unidades informantes fueron 6 rectores y 83 docentes. Se diseñaron dos instrumentos de recolección de datos, tipo escala tipo Lickert. Los instrumentos fueron sometidos a validez y confiabilidad a través del método Alfa de Cronbach obteniéndose una confiabilidad para el instrumento dirigido a los rectores de 0,964 y 0,902 para los docentes.

\section{Hincapié Parejo, Nair Farides*}

Magister en Educación. Mención Gerencia de la Organizaciones Educativas. Especialista en Planeación Educativa y Planes de Desarrollo. Licenciada en Biología y Química. Docente de la Institución Educativa Distrital Beatriz Gutiérrez de Vives y del Colegio El Divino Niño. Santa Marta, Colombia.

\section{Edison Fernando Orellana Orellana**}

Magister en Administración de Empresas. Ingeniero Empresarial. Director de la Carrera de Administración de Empresas. Universidad Católica de Cuencas. Ecuador.

Carlos Patricio Orellana Orellana***

Magister en Administración de Empresas. Ingeniero Empresarial. Docente a tiempo completo de la Universidad Católica de Cuencas. Ecuador 
La alternativa algunas veces exhibe el mayor porcentaje para el grupo de rectores; mientras que para los docentes la mayor cantidad de respuestas estuvo orientada hacia la alternativa casi siempre. Se puntualiza que el clima organizacional se ubicó en un rango medianamente apropiado, pero en el extremo inferior (3.62).

Palabras clave: Clima organizacional, tipos de clima, dimensiones del clima, instituciones escolares, Colombia.

\title{
ORGANIZATIONAL CLIMATE IN THE EDUCATIONAL INSTITUTIONS OF SANTA MARTA, COLOMBIA
}

\begin{abstract}
The objective of the article is to determine the organizational climate in the school institutions of Santa Marta Colombia, under the theoretical foundations of authors, such as: Brunet (2008), Robbins and Coulter (2010), Chiavenato, (2006), Daft and Marcic, (2006), Goncalves (2007) among others. The research was descriptive with field design, transectional and non-experimental. The population consisted of six primary public basic educational units located in the city of Santa Marta. The reporting units were 6 rectors and 83 teachers. Two instruments of data collection, type scale type Lickert, were designed. The instruments were subjected to validity and reliability through the Cronbach's Alpha method, obtaining a reliability for the instrument addressed to the rectors of 0.964 and 0.902 for the teachers. The alternative sometimes exhibits the highest percentage for the group of rectors; while for teachers the most answers were oriented towards the alternative almost always. It is pointed out that the organizational climate was in a moderately appropriate range, but at the lower end (3.62).
\end{abstract}

Keywords: Organizational climate, types of climate, climate dimensions, school institutions, Colombia.

\section{INTRODUCCIÓN}

Se puede considerar, que gerenciar significa conducir o guiar la organización dentro de ciertos parámetros, con el propósito de lograr que las personas trabajen en función de alcanzar los objetivos organizacionales, mediante los procesos de planificación, organización, dirección y control. Esta conducción implica el uso eficaz y eficiente de los recursos disponibles (físicos, humanos, materiales, financieros), por lo que el gerente debe asumir el reto de conducir la organización al éxito y enfrentarse a múltiples variables que atentan contra el buen funcionamiento de la misma, entre ellas el clima organizacional.

A esta aseveración no escapan las instituciones educativas, donde en la actualidad se le está dando importancia a la valoración del clima organizacional, ya que brinda vitalidad a los sistemas organizativos, permitiendo una mayor productividad del recurso humano; 
constituyéndose así, en un elemento esencial en el desarrollo de la estrategia organizacional planificada y posibilitando a los directores la obtención de una visión futura de la organización y logrando una mayor eficiencia organizativa.

De igual manera, el clima organizacional en las instituciones educativas es de vital importancia para incrementar el desempeño laboral de su personal, aumentando sus capacidades para resolver problemas cada vez más complejos y adaptarse a sus funciones laborales y al entorno donde se desenvuelven. Asimismo, el buen funcionamiento de la institución, dependerá del ambiente de trabajo que puedan percibir los docentes y el resto del personal, esto hará que se sientan comprometidos con las normas y reglamentos que la misma establece, o bien generar desapego e indiferencia hacia las mismas.

Por otra parte, es pertinente señalar que las personas que hacen parte de las organizaciones, especialmente las educativas, revelan informaciones y acontecimientos que suceden a su alrededor, así mismo, interactúan con distintos factores laborales, tales como: estilo de jefe, rigidez de la estructura organizacional entre otros, que influyen en su percepción, por lo que el desempeño de los empleados no solo es producto de su análisis, sino también del clima donde trabaja.

Desde este punto de vista, la clave fundamental es el trabajo en equipo, en el que convergen diversos elementos que orientan el alcance de los objetivos institucionales, partiendo de factores relevantes que permiten que las políticas organizacionales impacten en la sociedad, generando cambios sustanciales en el ámbito educativo. En otras palabras, el éxito que puede tener la organización al alcanzar sus metas al igual que satisfacer su responsabilidad social depende en gran medida del liderazgo gerencial y del buen clima laboral existente en la organización. Por ende, se hace necesario contar con personas en la alta gerencia con habilidades personales y profesionales para dinamizar los recursos, canalizar y dirigir procesos organizacionales.

Ahora bien, el clima organizacional según Davis y Newstrom (2004), así como Robbins y Coulter (2010), es definido como un conjunto de prioridades o características del ambiente interno laboral, percibidas directa o indirectamente por los empleados de una organización, que se supone son una fuerza que influye en la conducta del empleado. Quiere decir entonces, que para mantener un clima laboral agradable, es importante que el gerente educativo fomente una estructura funcional, además de desarrollar ciertas medidas, que facilitan la integración de todo el talento humano, desde los niveles directivos, hasta el último de los trabajadores, donde la motivación, la comunicación, sentido de pertenencia y trabajo en equipo permeen en los propósitos de la institución con la finalidad de brindar una educación de calidad.

A este respecto, la Unión de las Naciones para la Educación Científica y Cultural (UNESCO, 2006: 99), plantea que "la calidad educativa se centra en la gestión gerencial del directivo para movilizar la institución, promoviendo la condición humana a través de un proceso de reflexión colectiva con los docentes en base a valores y procesos de relevancia administrativa", con la finalidad de alcanzar el éxito ante cualquier actividad emprendida. 
Así mismo, Brunet (2008), menciona a los investigadores: James y George (2006) quienes definen desde tres puntos de vista el clima organizacional: medida múltiple de los atributos organizacionales, la percepción de los atributos individuales y la percepción de los atributos de la organización. Tomando en consideración el segundo referente, es quizás uno de los aspectos que enmarca el clima organizacional, debido a que son las personas quienes, a partir de sus actitudes, experiencias, interactuar, expresan sus apreciaciones del ambiente en los que se desenvuelven, elementos de gran relevancia para conocer cómo se lideran los procesos en la organización.

Desde esta perspectiva, Koontz y col (2007), señalan que el clima organizacional es la percepción de un grupo de personas que forman parte de una organización, con base a la cual establecen diversas interacciones relacionadas al contexto laboral. Asimismo, Chiavenato (2006), expone que el clima organizacional es aquel que representa las cualidades o propiedades del ambiente organizacional que son percibidas o experimentadas por los miembros de dicha organización; es decir, a las propiedades motivacionales del ambiente organizacional representando la suma del estándar total de expectativas y valores de incentivos que existen en determinado conjunto organizacional.

Por tanto, la presente investigación se propone determinar el clima organizacional en las instituciones escolares de Santa Marta, Colombia, con la finalidad de aportar estrategias, soluciones que fomenten un mejor funcionamiento y relaciones óptimas entre el personal y gerentes, líderes o personal directivo, en pro de un mejor desempeño laboral y satisfacción por los logros cumplidos. Sobre la base de lo expuesto, se formulan las siguientes interrogantes: ¿Cuáles son los tipos de clima organizacional presentes en las instituciones escolares en Santa Marta Colombia? y ¿Cuáles son las dimensiones del clima organizacional en las instituciones escolares en Santa Marta, Colombia?

\section{Algunas consideraciones teóricas}

El clima organizacional es un tema de gran importancia hoy en día para todas las organizaciones, las cuales buscan un continuo mejoramiento del ambiente laboral, para así alcanzar un aumento de productividad, sin perder de vista el recurso humano. Para explorar este interesante tema se contará con la opinión de distintos e importantes estudiosos del tema y también con las definiciones dadas por destacados autores contemporáneos, acerca de la temática en estudio.

Desde un punto de vista general el clima organizacional se refiere a las propiedades del ambiente de trabajo que perciben los empleados, Gibson y col (2006:69), argumentan que el clima organizacional es "el conjunto de propiedades del ambiente laboral percibidas directa o indirectamente por los empleados, que se supone es una fuerza importante que influye en la conducta del empleado". Mientras que Hitt y col (2006), plantean que clima organizacional puede ser entendido como un fenómeno socialmente construido, que surge de las interacciones individuo-grupo-condiciones de trabajo, lo que da como resultado un 
significado a las experiencias individual y grupal, debido a que lo que pertenece y ocurre en la organización afecta e interactúa con todo. Los resultados organizacionales son precisamente consecuencia de estas interacciones, que se dan de manera dinámica, cambiante y cargada de afectividad.

Por su parte, Brunet (2008) define el clima organizacional como la naturaleza subjetiva de los atributos organizacionales estipulados por la percepción de los individuos, bajo la influencia de numerosos aspectos y condiciones del medio laboral, caracterizados por un conjunto heterogéneo de dimensiones conformadas por diversos estímulos. Este puede ser sentido por los individuos sin que estén conscientes de los elementos que lo componen.

De igual manera, Gonçalves (2007) describe el clima organizacional como un fenómeno interviniente que media entre los factores del sistema organizacional y las tendencias motivacionales que se traducen en un comportamiento el cual tiene consecuencias sobre la organización. Litwin y Stringer (1968), citados por Gonçalves (2007), definen clima organizacional como un conjunto de propiedades medibles del medio ambiente de trabajo, percibidas directa o indirectamente por las personas que trabajan en la organización y que influyen su motivación y comportamiento. Estas definiciones, considera como elemento fundamental las percepciones que el trabajador tiene de las estructuras y procesos que ocurren en su medio laboral e igualmente las percepciones del trabajador de los factores organizacionales.

Asimismo, Chiavenato (2011), sostiene que el individuo desea sentir que la organización los apoya y se preocupan por sus necesidades y problemas, por tanto, se puede indicar que pasa que las organizaciones obtengan el éxito, sus administradores deben conocer los individuos y las personas que integran la institución, así como no pueden perder de vista el puesto que tengan dentro de la organización puesto que el mismo influirá de manera determinante en su forma de ver las cosas, en sus observaciones en relación con los hechos que suceden dentro del sistema organizacional.

En el ámbito de las organizaciones educativas, Ojeda (2014) señala que el clima organizacional en el ambiente de una institución educativa está determinado por todos aquellos factores físicos, elementos estructurales, personales, funcionales y culturales de la institución que, integrados interactivamente en un proceso dinámico específico, confieren un peculiar estilo o tono a la institución, condicionante a su vez de distintos productos educativos. Por su parte García (2009) indica que el clima en las organizaciones educativas, se refiere al tipo de ambiente que se presenta en la misma, el tipo de trato, las relaciones de colaboración y otros factores importantes que permiten para mantener una convivencia positiva o no, influyendo en los procesos de grupales que allí acontecen.

Para Daft y Marcic (2006) el clima organizacional es visto como el ambiente que se percibe como consecuencia de la interacción de los diferentes componentes organizativos educacionales, en especial de las relaciones interpersonales. Señala, que dentro de la institución se observan cuatro dimensiones: su ecología aspectos como, los físicos y materiales, su medio es decir, la dimensión social, las características del individuo en ambiente, su sistema social 
tales como las relaciones de personas o grupos de su cultura y la dimensión social interesada en los sistemas de creencias, valores y estructuras cognitivas.

Por consiguiente, un clima favorable en las instituciones escolares se caracteriza por partir de las relaciones interpersonales cordiales y positivas, basadas en la confianza y respeto mutuo, la cooperación y en la direccionalidad del desarrollo de procesos de mejora en las organizaciones. De allí que, toda organización y especialmente las educativas necesitan de un clima que asegure el bienestar de todos los miembros que forman parte de ella.

En este sentido, según los autores analizados el clima organizacional es un factor determinante en las relaciones laborales dentro de cualquier organización, como es el caso específico de las instituciones educativas. Pero, como cada situación que se presenta en la misma es distinta, sus componentes suelen modificarse, dependiendo de diversos factores, ya sea producto del liderazgo directivo o por la forma de comunicación entre sus miembros o por las relaciones interpersonales que se susciten dentro de la institución.

Estos enfoques, coinciden y resaltan la importancia de la percepción de las personas que hacen parte de la organización sobre lo que ocurre en la convivencia entre ellos y su relación con la estructura organizacional. En otras palabras, no tiene que ver solamente en cómo es la vida en la organización, sino en cómo las personas lo perciben, puesto que estas percepciones permearán en los comportamientos, actitudes y resultados de los equipos de trabajo. De manera que se asumen los planteamientos realizados por Brunet (2008), por cuanto considera que el clima organizacional influye en el comportamiento manifiesto de los miembros, a través de percepciones estabilizadas que filtran la realidad y condicionan los niveles de motivación laboral y rendimiento profesional.

Por lo antes expuesto, es necesario que el clima organizacional de las instituciones educativas se torne positivo, ya que así los docentes trabajan motivados y rinden más, lo que genera calidad en la educación impartida. Desde este punto de vista, los gerentes educativos deben ser capaces de formular sus propias estrategias para la resolución de conflictos, gestionar los recursos de la institución para que las actividades planificadas se ejecuten, no dejarse llevar por suposiciones de terceros y enfrentar a tiempo las debilidades que puedan existir.

Bajo este criterio, se infiere que es necesario que la institución educativa brinde un clima confortable, agradable, receptivo, donde se propicien las relaciones de grupo de manera proactiva, ya que la percepción que se tenga de la misma incide de manera determinante en la conducta de los docentes y demás miembros que en ella laboran.

\section{Aspectos metodológicos}

La investigación fue descriptiva con diseño de campo, transversal y no experimental. La población estuvo conformada por las instituciones educativas agrupadas en la localidad 3,

ORATORES ISSN Impreso: 2644-3988 ISSN Electrónico: L-2644-3988 Año 8. Número 9. Diciembre 2018 - Mayo 2019 
que cuentan con el Nivel Básico Primaria, ubicadas en la ciudad de Santa Marta, Colombia. De acuerdo a la Secretaría de Educación Distrital de Santa Marta estas ascienden a diecinueve (19) instituciones educativas. Para abordar la población se procedió a realizar un muestreo no probabilístico casual o incidental, para determinar las instituciones educativas que formaron parte del estudio. En este sentido, se tomaron seis (6) instituciones educativas a nivel de educación básica primaria públicas, ubicadas la comuna 7, de la localidad 3, de la ciudad de Santa Marta. Esta selección se hizo siguiendo los criterios de: accesibilidad, ya que se encuentran agrupada en una misma zona geográfica y porque cuentan con el mayor número de estudiantes y docentes.

Cuadro 1. Distribución de la muestra

\begin{tabular}{|l|c|c|}
\hline \multicolumn{1}{|c|}{ Instituciones Educativas. Localidad 3. Comuna 7 } & $\begin{array}{c}\text { Unidades } \\
\text { informantes }\end{array}$ & $\begin{array}{c}\text { Unidades } \\
\text { informantes }\end{array}$ \\
\hline Institución Educativa Distrital Camilo Torres & 26 & 1 \\
\hline Institución Educativa Distrital Beatriz Gutiérrez de Vives & 10 & 1 \\
\hline Institución Educativa Distrital Simón Bolívar & 11 & 1 \\
\hline Institución Educativa Distrital La Quinina & 7 & 1 \\
\hline Institución Educativa Distrital Gabriela Mistral & 12 & 1 \\
\hline Institución Educativa Distrital José Laborde Gnecco & 17 & 6 \\
\hline Total: & 83 & 1 \\
\hline
\end{tabular}

Fuente: Elaboración propia, a partir de los datos obtenidos (2017). Alcaldía de Santa Marta. Secretaría de Educación. www.educacion.santamarta.gov.co/colegios/2017.

En cuanto a las unidades informantes, en el cuadro 1, se visualizan las instituciones seleccionadas y la distribución de docentes y rectores, de acuerdo a los datos suministrados por la Secretaría de Educación de la Alcaldía de Santa Marta. De acuerdo a lo expresado se le aplicó el instrumento a 83 docentes y a 6 rectores de estas instituciones educativas. El cuestionario estuvo estructurado por 48 aseveraciones correspondientes a los indicadores planteados. En el instrumento se utilizó una escala tipo Lickert con cinco alternativa de respuesta: Siempre, casi siempre, algunas veces, casi nunca y nunca. Para establecer la escala de evaluación de los resultados, se procedió al cálculo del baremo. Este procedimiento se realizó para conformar el baremo, aplicándolo a todas las opciones de respuestas, hasta alcanzar la máxima puntuación posible (ver cuadro 2). Este fue utilizado para interpretar la media aritmética de los indicadores, dimensiones y la variable (Tapia, 2007).

Cuadro 2. Categoría de respuestas

\begin{tabular}{|c|c|c|c|}
\hline Puntaje & Alternativas & Rango & \\
\hline 1 & Nunca & $1,00-1,79$ & \\
\hline 2 & Casi nunca & $1,80-2,60$ & Inapropiado \\
\hline 3 & Algunas veces & $2,61-3,40$ & \\
\hline 4 & Casi siempre & $3,41-4,20$ & Medianamente apropiado \\
\hline 5 & Siempre & $4,21-5,00$ & Apropiado \\
\hline
\end{tabular}

Fuente: Elaboración propia, a partir de Tapia (2007). 
Una vez elaborado los instrumentos, se llevó a cabo la validez a través de la consulta a cinco expertos para que evaluaran la correspondencia de los ítems planteados con respecto a las bases teóricas expuestas y a la variable de estudio planteada. Luego se aplicó una prueba piloto a treinta (30) sujetos pertenecientes a la población de docentes y a seis (6) rectores; se calculó la confiabilidad a través del método Alfa de Cronbach obteniéndose como resultado 0,902 (docentes) y 0,964 (rectores), indicando muy alta confiabilidad.

\section{RESULTADOS DE LA INVESTIGACIÓN}

\section{Tipos de clima organizacional presente en las instituciones escolares en Santa Marta, Colombia.}

Con respecto a los tipos de clima organizacional, Brunet (2008) desarrolló una tipología a lo largo de un continuo que se extiende desde un clima muy autoritario hasta uno muy participativo, dando lugar a cuatro tipos básicos de clima: autoritario explotador, autoritario paternalista, participativo consultivo y participativo de grupo.

A continuación en la tabla 1, se exhiben los resultados del primer indicador: Autoritario explotador. Se observa en la referida tabla como $66,6 \%$ de los rectores afirman que siempre se percibe confianza hacia el personal docente, mientras que un 33,4\% señaló que algunas veces se confía en los docentes. En tanto un menor porcentaje de los docentes opinó que en la institución donde laboran se caracteriza por tener un clima organizacional donde siempre (41\%) y casi siempre $(21,7 \%)$ se percibe confianza hacia ellos. El resto, no menos importante, argumentó que casi nunca $(18,1 \%)$, algunas veces $(16,9 \%)$ y nunca $(2,4 \%)$ perciben tal confianza.

Tabla 1. Autoritario explotador

\begin{tabular}{|c|c|c|c|c|c|c|c|c|c|c|c|c|}
\hline \multirow{4}{*}{$\begin{array}{r}\text { Muestra } \\
\text { Aseveraciones }\end{array}$} & \multicolumn{10}{|c|}{ Alternativas de respuestas } & \multirow{2}{*}{\multicolumn{2}{|c|}{$\begin{array}{l}\text { Media } \\
\text { aseveración }\end{array}$}} \\
\hline & \multicolumn{2}{|c|}{ Siempre } & \multicolumn{2}{|c|}{ Casi Siempre } & \multicolumn{2}{|c|}{ Algunas veces } & \multicolumn{2}{|c|}{ Casi nunca } & \multicolumn{2}{|c|}{ Nunca } & & \\
\hline & Rector & Doc. & Rector & Doc. & Rector & Doc. & Rector & Doc. & Rector & Doc. & \multirow{2}{*}{ Rector } & \multirow{2}{*}{ Doc. } \\
\hline & $\%$ & $\%$ & $\%$ & $\%$ & $\%$ & $\%$ & $\%$ & $\%$ & $\%$ & $\%$ & & \\
\hline $\begin{array}{c}\text { Se percibe } \\
\text { confianza hacia } \\
\text { el personal } \\
\text { docente }\end{array}$ & 66.6 & 41.0 & - & 21.7 & 33.4 & 16.9 & - & 18.1 & - & 2.3 & 4.33 & 3.82 \\
\hline $\begin{array}{l}\text { El control de } \\
\text { las actividades } \\
\text { académicas } \\
\text { la tiene el } \\
\text { Rector(a) }\end{array}$ & - & 8.4 & 33.3 & 31.3 & 50.0 & 30.1 & 16.7 & 9.6 & - & 20.6 & 3.17 & 3.00 \\
\hline $\begin{array}{l}\text { Las actividades } \\
\text { se realizan bajo } \\
\text { un ambiente } \\
\text { de cordialidad } \\
\text { permanente }\end{array}$ & 66.6 & 41.0 & - & 12.0 & 16.7 & 15.7 & 16.7 & 25.3 & - & 6.0 & 4.17 & 3.57 \\
\hline (\%) Indicador & 44.4 & 30.1 & 11.1 & 21.7 & 33.4 & 20.9 & 11.1 & 17.7 & - & 9.6 & & \\
\hline \multicolumn{11}{|c|}{ Media del indicador. Rectores/ Docentes } & 3.89 & 3.46 \\
\hline
\end{tabular}

Fuente: Elaboración propia a partir de los datos obtenidos del instrumento aplicado (2017) 
En cuanto a la segunda aseveración, los resultados demostraron que según opinión del $50 \%$ de los rectores, el control de las actividades académicas de la institución algunas veces lo tienen ellos, el $33,3 \%$ casi siempre y el $16,7 \%$ casi nunca ejercen tal control. A su vez el 31,3\% de los docentes piensan que casi siempre los rectores controlan las actividades desarrolladas desde el punto de vista académico, el 30,1\% piensan que algunas veces y solo el 20,6\% opinó que nunca se evidencia este control.

Para finalizar con este indicador, se precisa en la tabla 1, que un grupo alto de rectores $(66,6 \%)$ argumenta que siempre las actividades se realizan bajo un ambiente de cordialidad permanente. Solo un grupo menor de rectores señaló que algunas veces $(16,7 \%)$ y casi nunca $(16,7 \%)$, se visualizaba esta circunstancia. Con la misma orientación positiva, el $41 \%$ y el $12 \%$ de los docentes respectivamente afirmaron que siempre y casi siempre la institución se caracterizaba por mostrar un ambiente cordial a la hora de realizar las actividades propias del quehacer académico. El resto mostró una actitud con orientación negativa hacia la aseveración presentada.

Tabla 2. Autoritario paternalista

\begin{tabular}{|c|c|c|c|c|c|c|c|c|c|c|c|c|}
\hline \multirow{4}{*}{$\begin{array}{l}\text { Muestra } \\
\text { Aseveraciones }\end{array}$} & \multicolumn{10}{|c|}{ Alternativas de respuestas } & \multirow{2}{*}{\multicolumn{2}{|c|}{$\begin{array}{c}\text { Media } \\
\text { aseveración }\end{array}$}} \\
\hline & \multicolumn{2}{|c|}{ Siempre } & \multicolumn{2}{|c|}{ Casi Siempre } & \multicolumn{2}{|c|}{ Algunas veces } & \multicolumn{2}{|c|}{ Casi nunca } & \multicolumn{2}{|c|}{ Nunca } & & \\
\hline & Rector & Doc. & Rector & Doc. & Rector & Doc. & Rector & Doc. & Rector & Doc. & \multirow{2}{*}{ Rector } & \multirow{2}{*}{ Doc. } \\
\hline & $\%$ & $\%$ & $\%$ & $\%$ & $\%$ & $\%$ & $\%$ & $\%$ & $\%$ & $\%$ & & \\
\hline $\begin{array}{c}\text { Utiliza la } \\
\text { recompensa } \\
\text { para motivar } \\
\text { al personal } \\
\text { docente }\end{array}$ & - & 9.0 & 16.7 & 19.3 & 50.0 & 25.3 & 16.7 & 15.7 & 16.7 & 33.7 & 2.67 & 2.44 \\
\hline $\begin{array}{l}\text { Las normas } \\
\text { institucionales } \\
\text { solo están } \\
\text { establecidas } \\
\text { para guiar el } \\
\text { comportamiento } \\
\text { del personal } \\
\text { docente y } \\
\text { administrativo }\end{array}$ & 33.3 & 25.3 & 45.8 & 45.8 & 20.9 & 21.7 & - & 6.0 & - & 1.2 & 3.67 & 3.88 \\
\hline $\begin{array}{c}\text { La } \\
\text { comunicación } \\
\text { con los } \\
\text { docentes es solo } \\
\text { para discutir la } \\
\text { labor diaria en } \\
\text { la institución }\end{array}$ & - & 15.7 & - & 27.7 & 50.0 & 28.9 & 33.3 & 22.9 & 16.7 & 4.8 & 2.33 & 3.27 \\
\hline (\%) Indicador & 11.1 & 15.7 & 20.8 & 30.9 & 40.3 & 25.3 & 16.7 & 14.9 & 11.1 & 13.2 & & \\
\hline Media del indica & dor. Rec & tores/1 & Docentes & & & & & & & & 2.89 & 3.19 \\
\hline
\end{tabular}

Fuente: Elaboración propia a partir de los datos obtenidos del instrumento

En la tabla 2, se detallan los resultados para las tres aseveraciones presentadas para caracterizar el Autoritario paternalista, donde el 50\% de los rectores algunas veces utilizan recompensa para motivar al personal docente, mientras que un porcentaje inferior indicó que 
casi siempre $(16,7 \%)$, casi nunca $(16,7 \%)$ y nuca $(16,7 \%)$ ofrecía tales recompensas. En contraposición, un alto porcentaje de docentes señaló que nunca $(33,7 \%)$, algunas veces $(25,3 \%)$ y casi nunca $(15,7 \%)$ el rector utilizaba recompensas para motivarlos. Solo un grupo menor argumento que casi siempre (19,3\%) y siempre (6\%), esto se hacía.

Por otra parte, un grupo importante de rectores argumentó que casi siempre $(45,8 \%)$ y siempre $(33,3 \%)$ las normas institucionales están establecidas para guiar el comportamiento del personal docente y administrativo. Po su parte, el $45,8 \%$ y el $25,3 \%$ de los docentes respectivamente corroboraron esta posición de los rectores. Solo un menor porcentaje mantuvo una posición neutral y negativa al respecto.

En cuanto a la tercera aseveración, el 50\% de los rectores mantuvieron una posición neutral al indicar que algunas veces la comunicación con los docentes es para discutir la labor diaria en la institución. A lo que opinaron los docentes entrevistados de manera contraria, ya que algunas veces $(28,9 \%)$ y casi nunca $(22,9 \%)$ esto es así. Sin embargo para el resto $(27,7 \%)$ casi siempre y siempre $(15,7 \%)$, el rector se comunica con ellos solo para dar instrucciones.

Como comentario, se puede decir que el ambiente que rodea al tipo de clima autoritario es útil, para imponer reglas, normas, valores organizacionales, funciona mejor con docentes nuevos y menos capacitados, y con el personal con desempeño bajo o deficiente. El clima autoritario, se produce cuando el directivo no tiene confianza en su equipo de docentes, ya sea porque considera que solo la dirección conoce de procedimientos, porque el personal docente es nuevo en la institución, o también porque se pretenden sembrar temor entre los docentes, quienes deben únicamente cumplir con su deber al impartir las clases.

Tabla 3. Participativo consultivo

\begin{tabular}{|c|c|c|c|c|c|c|c|c|c|c|c|c|}
\hline \multirow{4}{*}{ Aseveraciones } & \multicolumn{10}{|c|}{ Alternativas de respuestas } & \multirow{2}{*}{\multicolumn{2}{|c|}{$\begin{array}{l}\text { Media } \\
\text { aseveración }\end{array}$}} \\
\hline & \multicolumn{2}{|c|}{ Siempre } & \multicolumn{2}{|c|}{ Casi Siempre } & \multicolumn{2}{|c|}{ Algunas veces } & \multicolumn{2}{|c|}{ Casi nunca } & \multicolumn{2}{|c|}{ Nunca } & & \\
\hline & Rector & Doc. & Rector & Doc. & Rector & Doc. & Rector & Doc. & Rector & Doc. & & \\
\hline & $\%$ & $\%$ & $\%$ & $\%$ & $\%$ & $\%$ & $\%$ & $\%$ & $\%$ & $\%$ & Rector & Doc. \\
\hline $\begin{array}{l}\text { Se genera un } \\
\text { ambiente de } \\
\text { trabajo basado } \\
\text { en la confianza } \\
\text { y el respeto } \\
\text { mutuo entre el } \\
\text { personal } \\
\end{array}$ & 50.0 & 39.8 & 33.3 & 39.8 & 16.7 & 13.3 & - & 6.0 & - & 1.2 & 4.33 & 4.11 \\
\hline $\begin{array}{l}\text { Hay incentivos } \\
\text { a las ideas y } \\
\text { opiniones de } \\
\text { los docentes } \\
\text { relacionadas } \\
\text { al buen } \\
\text { funcionamiento } \\
\text { institucional }\end{array}$ & 33.3 & 15.7 & 33.3 & 20.5 & 16.7 & 27.7 & 16.7 & 16.9 & - & 19.3 & 3.83 & 2.96 \\
\hline
\end{tabular}




\begin{tabular}{|c|c|c|c|c|c|c|c|c|c|c|c|c|}
\hline $\begin{array}{c}\text { Se propicia un } \\
\text { ambiente de } \\
\text { trabajo donde } \\
\text { el docente } \\
\text { se siente } \\
\text { coparticipe del } \\
\text { funcionamiento } \\
\text { de la institución }\end{array}$ & 50.0 & 16.9 & 16.7 & 44.6 & 33.3 & 31.3 & - & 7.2 & - & - & 4.17 & 3.71 \\
\hline (\%) Indicador & $\mathbf{4 4 . 4}$ & $\mathbf{2 4 . 1}$ & $\mathbf{2 7 . 8}$ & $\mathbf{3 4 . 9}$ & $\mathbf{2 2 . 2}$ & $\mathbf{2 4 . 1}$ & $\mathbf{5 . 6}$ & $\mathbf{1 0 . 0}$ & $\mathbf{-}$ & $\mathbf{6 . 8}$ & & \\
\hline \\
Media del indicador. Rectores/ Docentes
\end{tabular}

Fuente: Elaboración propia a partir de los datos obtenidos del instrumento

El indicador participativo consultivo, fue evaluado a través de tres afirmaciones. En este sentido, al observar los datos presentados en la tabla 3, en cuanto a si se genera un ambiente de trabajo basado en la confianza y el respeto mutuo entre el personal, el 50\% de los rectores entrevistados dieron como respuesta siempre, el 33,3\% como casi siempre y el $16,7 \%$ como algunas veces. Mientras que un grupo de docentes (39,8\%), opinó que siempre y el mismo porcentaje señaló que casi siempre se genera ese ambiente de trabajo.

Otra aseveración presentada se refiere a si hay incentivos a las ideas y opiniones de los docentes relacionadas al buen funcionamiento institucional. Los resultados indican que, por una parte, el 33,3\% de los rectores piensan que siempre y otro grupo igual $(33,3 \%)$ que casi siempre hay incentivo a las ideas de los docentes.

Frente a estos resultados, se evidencia un mayor grupo de docentes con opinión negativa con respecto a la segunda aseveración. Si bien se observa que el 36,2\% del personal docente entrevistado señaló casi siempre (20,5\%) y siempre (15,7\%); una cantidad superior del personal docente expresó respuestas con orientación negativa. Así, los docentes indicaron que nunca $(19,3 \%)$, casi nunca $(16,9 \%)$ y algunas veces $(27,7 \%)$ se incentivan sus opiniones referidas al buen funcionamiento institucional.

Continuando con el último indicador: Participación en grupo, se tiene que la primera aseveración fue evaluada positivamente por los rectores, quienes manifestaron que casi siempre (50\%) y siempre (33,3\%) a los docentes se les permite discutir con ellos los problemas relacionados al trabajo diario. Mientras que para el $43,4 \%$ y para el $28,9 \%$ de los docentes casi siempre y algunas veces esto ocurre.

Por otra parte, los rectores tienen opiniones favorables con respecto a la segunda aseveración. Para ellos, siempre (50\%) y casi siempre (16,7\%) se fomenta la motivación del personal a través de la participación activa de todos los miembros de la institución. Nótese como un 16,7\% indicó algunas veces y otro 16,7\% que nunca se fomenta tal motivación. En tanto para el $38,6 \%$ de los docentes, casi siempre y algunas veces $(34,9 \%)$ el rector los motiva a participar activamente. 
Tabla 4. Participativo en grupo

\begin{tabular}{|c|c|c|c|c|c|c|c|c|c|c|c|c|}
\hline \multirow{4}{*}{$\begin{array}{r}\text { Muestra } \\
\text { Aseveraciones }\end{array}$} & \multicolumn{10}{|c|}{ Alternativas de respuestas } & \multirow{2}{*}{\multicolumn{2}{|c|}{$\begin{array}{c}\text { Media } \\
\text { aseveración }\end{array}$}} \\
\hline & \multicolumn{2}{|c|}{ Siempre } & \multicolumn{2}{|c|}{ Casi Siempre } & \multicolumn{2}{|c|}{ Algunas veces } & \multicolumn{2}{|c|}{ Casi nunca } & \multicolumn{2}{|c|}{ Nunca } & & \\
\hline & Rector & Doc. & Rector & Doc. & Rector & Doc. & Rector & Doc. & Rector & Doc. & \multirow{2}{*}{ Rector } & \multirow{2}{*}{ Doc. } \\
\hline & $\%$ & $\%$ & $\%$ & $\%$ & $\%$ & $\%$ & $\%$ & $\%$ & $\%$ & $\%$ & & \\
\hline $\begin{array}{l}\text { A los docentes } \\
\text { se les permite } \\
\text { discutir con } \\
\text { los directivos } \\
\text { los problemas } \\
\text { relacionados al } \\
\text { trabajo diario }\end{array}$ & 33.3 & 21.7 & 50.0 & 43.4 & 16.7 & 28.9 & - & 4.8 & - & 1.2 & 4.17 & 3.80 \\
\hline $\begin{array}{l}\text { Se fomenta } \\
\text { la motivación } \\
\text { del personal } \\
\text { a través de la } \\
\text { participación } \\
\text { activa de } \\
\text { todos los } \\
\text { miembros de la } \\
\text { institución }\end{array}$ & 50.0 & 19.3 & 16.7 & 38.6 & 16.7 & 34.9 & - & 4.8 & 16.7 & 2.4 & 4.00 & 3.67 \\
\hline $\begin{array}{c}\text { Se fomenta } \\
\text { la creación } \\
\text { de equipos } \\
\text { cohesionados }\end{array}$ & 16.7 & 20.5 & 33.3 & 44.6 & 50.0 & 26.5 & - & 6.0 & - & 2.4 & 3.67 & 3.75 \\
\hline (\%) Indicador & 33.3 & 20.5 & 33.3 & 42.2 & 27.8 & 30.1 & - & 5.2 & 5.6 & 2.0 & & \\
\hline \multicolumn{11}{|c|}{ Media del indicador. Rectores/ Docentes } & 3.89 & 3.46 \\
\hline
\end{tabular}

Fuente: Elaboración propia a partir de los datos obtenidos del instrumento

Por último, el 50\% de los rectores piensan que algunas veces se fomenta la creación de equipos cohesionados para alcanzar los objetivos institucionales, el resto estuvo distribuido en las alternativas casi siempre (33,3\%) y siempre (16,7\%). En este sentido, el personal docente opinó favorablemente, donde indicaron con las alternativas casi siempre $(44,6 \%)$, algunas veces (26,5\%) y siempre (20,5\%) que se fomenta la creación de estos equipos de trabajo. Muy bajo porcentaje opinó casi nunca y nunca.

Con respecto a los resultados evidenciados, se puede puntualizar que el tipo de clima denominado participativo, bien sea el participativo consultivo o en grupo, de acuerdo a Chiavenato (2002) es uno de los más favorables para la organización, donde se toma en consideración la opinión de los miembros de la misma. En este orden de ideas García y col (2002), argumentan que este clima de participación coadyuva a que los docentes resuelvan problemas y ejecuten sus actividades sintiéndose motivados y responsables de la conducción de las mismas.

Cerrando la discusión de los resultados, en la tabla 5, se aprecia en detalle la media para los cuatro indicadores seleccionados, donde los valores de la media aritmética obtenidos para el grupo de rectores (3.71) fue superior a la obtenida en las respuestas dadas por los docentes (3.50), ubicándose en el rango medianamente apropiado. En detalle, se observan los valores del promedio del indicador autoritario explotador, lo cual indica que este tipo de categoría no es una característica del clima organizacional de las instituciones abordadas enmarcándose 
dentro de la tendencia medianamente apropiada. Sin embargo, el tipo de clima autoritario paternalista se ubicó en un rango inapropiado infiriéndose su presencia en las instituciones educativas estudiadas según el baremo diseñado para tal fin.

Tabla 5. Resumen: Tipos de clima organizacional

\begin{tabular}{|c|c|c|}
\hline Tipos de climas & Rectores & Personal Docente \\
\hline Autoritario explotador & 3.89 & 3.46 \\
\hline Autoritario paternalista & 2.89 & 3.19 \\
\hline Participativo consultivo & 4.11 & 3.59 \\
\hline Participativo en grupo & 3.96 & 3.74 \\
\hline Media & 3.71 & 3.50 \\
\hline
\end{tabular}

Fuente: Elaboración propia

En cuanto al tipo de clima participativo consultivo y en grupo se observa la clara tendencia de los valores en posicionare en un rango medianamente apropiado, donde el mayor valor estuvo representado por las respuestas dadas por los rectores. Lo anterior permite señalar que estos tipos de clima se hacen presentes en las instituciones escolares estudiadas.

Los resultados anteriores demuestran lo que señala Brunet (2008) al indicar que cualquiera de los tipos de clima, puede ser utilizado, ninguno es mejor que el otro, depende de la habilidad del gerente y de las circunstancias que lo lleven a asumirlo en un momento determinado, de manera que actuar bajo el perfil de alguno de alguno de ellos no implica el rechazo automático de los otros.

En la sección que se presenta a continuación, se identifican las dimensiones del clima organizacional. De acuerdo a Gonçalves (2007) estas dimensiones: Estructura organizacional, Responsabilidad, Recompensa, Riesgo, Calor y apoyo y Conflicto permiten trazar lo más puntualmente posible la imagen del clima en una organización.

Tabla 6. Estructura organizacional

\begin{tabular}{|c|c|c|c|c|c|c|c|c|c|c|c|c|}
\hline \multirow{4}{*}{ Aseveraciones } & \multicolumn{10}{|c|}{ Alternativas de respuestas } & \multirow{2}{*}{\multicolumn{2}{|c|}{$\begin{array}{l}\text { Media } \\
\text { aseveración }\end{array}$}} \\
\hline & \multicolumn{2}{|c|}{ Siempre } & \multicolumn{2}{|c|}{ Casi Siempre } & \multicolumn{2}{|c|}{ Algunas veces } & \multicolumn{2}{|c|}{ Casi nunca } & \multicolumn{2}{|c|}{ Nunca } & & \\
\hline & Rector & Doc. & Rector & Doc. & Rector & Doc. & Rector & Doc. & Rector & Doc. & & \\
\hline & $\%$ & $\%$ & $\%$ & $\%$ & $\%$ & $\%$ & $\%$ & $\%$ & $\%$ & $\%$ & Rector & Doc. \\
\hline $\begin{array}{l}\text { Hay presencia } \\
\text { de normas } \\
\text { claras que } \\
\text { benefician } \\
\text { el ambiente } \\
\text { laboral }\end{array}$ & 16.7 & 32.5 & 33.3 & 32.5 & 33.3 & 27.7 & 16.7 & 4.8 & - & 2.4 & 3.50 & 3.88 \\
\hline $\begin{array}{l}\text { Los objetivos } \\
\text { institucionales } \\
\text { guían el } \\
\text { comportamiento } \\
\text { del personal } \\
\text { docente }\end{array}$ & 33.3 & 41.0 & 16.7 & 36.1 & 50.0 & 19.3 & - & 2.4 & - & 1.2 & 3.83 & 4.13 \\
\hline
\end{tabular}




\begin{tabular}{|c|c|c|c|c|c|c|c|c|c|c|c|c|}
\hline $\begin{array}{c}\text { Las tareas están } \\
\text { claramente } \\
\text { definidas }\end{array}$ & 16.7 & 41.0 & 50.0 & 32.5 & 33.3 & 22.9 & - & 2.4 & - & 1.2 & 3.83 & 4.73 \\
\hline (\%) Indicador & 22.2 & 38.2 & 33.3 & 33.7 & 38.9 & 23.3 & 5.6 & 3.2 & - & 1.6 & & \\
\hline \multicolumn{11}{|c|}{ Media del indicador. Rectores/ Docentes } & 3.72 & 4.25 \\
\hline
\end{tabular}

Fuente: Elaboración propia a partir de los datos obtenidos del instrumento

Para Gómez (2004), la estructura organizacional representa la percepción que tienen los miembros de la organización acerca de la cantidad de reglas, procedimientos, trámites y otras limitaciones que se ven enfrentados en el desarrollo de su trabajo.

En este sentido, los rectores entrevistados muestran opiniones contrarias referidas a la primera aseveración, donde un grupo afirma de manera positiva las respuestas y el mismo porcentaje lo hace con orientación negativa. Así se evidencia en la tabla 11, que según ellos, casi siempre $(33,3 \%)$ y siempre $(16,7 \%)$ hay presencia de normas claras que benefician el ambiente laboral. Sin embargo otros señalan, que algunas veces $(33,3 \%)$ y casi nunca $(16,7 \%)$, hay claridad en estas normas que rigen a las instituciones educativas estudiadas. Mientras que, de acuerdo a la percepción del personal docente, siempre $(32,5 \%)$ y casi siempre $(32,5 \%)$ se encuentran presente normas claras en la institución lo cual redunda en beneficio del ambiente laboral. El resto de los docentes asumieron una posición neutral y con tendencia negativa.

De nuevo en la segunda aseveración, se observa como los rectores tienen opiniones acentuadamente divididas. Para ellos, algunas veces (50\%) los objetivos institucionales guían el comportamiento del personal docente. Nótese como un 33,3\% indicó casi siempre y otro $16,7 \%$ que siempre estos objetivos se plasman como guía de comportamiento. En tanto para los docentes, siempre (41\%) y casi siempre $(36,1 \%)$ esto es así.

Por último, más de la mitad de los rectores entrevistados piensan que siempre (50\%) y casi siempre $(16,7 \%)$ las tareas están claramente definidas, el resto manifestó que algunas veces $(33,3 \%)$ esto era así. En este sentido, el personal docente coincidió con el grupo de rectores, dando opiniones favorablemente al respecto. Así, para ellos, siempre (41\%), casi siempre $(32,5 \%)$ y algunas veces $(22,9 \%)$ se definen las tareas a ejecutar de manera clara. Obsérvese que muy bajo porcentaje opinó casi nunca y nunca.

Tanto para Olaz (2010) como para Ortizy col(2010), esta dimensión cubre las directrices, las consignas y las políticas que puede emitir una organización y que afectan directamente la forma de llevar a cabo una tarea. Además está relacionada a la claridad de los métodos, los procesos y las funciones, así como de las políticas y directrices de la organización para que los empleados realicen adecuadamente su trabajo.

En cuanto a este indicador Responsabilidad, nótese en la tabla 7, como la mitad de la muestra de rectores coincidieron en afirmar que algunas veces el docente se responsabiliza por el trabajo que realiza, el 33,3\% piensa que siempre lo hace y un 16,7\% afirmó que nunca 
el docente asume tal responsabilidad. Contrapuesta a estas respuestas, los docentes opinan que siempre $(48,2 \%)$ y casi siempre $(41 \%)$ son responsables de su trabajo.

Tabla 7. Responsabilidad

\begin{tabular}{|c|c|c|c|c|c|c|c|c|c|c|c|c|}
\hline \multirow{4}{*}{$\begin{array}{r}\text { Muestra } \\
\text { Aseveraciones }\end{array}$} & \multicolumn{10}{|c|}{ Alternativas de respuestas } & \multirow{2}{*}{\multicolumn{2}{|c|}{$\begin{array}{c}\text { Media } \\
\text { aseveración }\end{array}$}} \\
\hline & \multicolumn{2}{|c|}{ Siempre } & \multicolumn{2}{|c|}{ Casi Siempre } & \multicolumn{2}{|c|}{ Algunas veces } & \multicolumn{2}{|c|}{ Casi nunca } & \multicolumn{2}{|c|}{ Nunca } & & \\
\hline & Rector & Doc. & Rector & Doc. & Rector & Doc. & Rector & Doc. & Rector & Doc. & \multirow{2}{*}{ Rector } & \multirow{2}{*}{ Doc. } \\
\hline & $\%$ & $\%$ & $\%$ & $\%$ & $\%$ & $\%$ & $\%$ & $\%$ & $\%$ & $\%$ & & \\
\hline $\begin{array}{l}\text { El docente es } \\
\text { responsable } \\
\text { por el trabajo } \\
\text { que realiza }\end{array}$ & 33.3 & 48.2 & - & 41.0 & 50.0 & 9.6 & 16.7 & - & - & 1.2 & 4.17 & 3.80 \\
\hline $\begin{array}{c}\text { Cuando el } \\
\text { personal } \\
\text { comete errores, } \\
\text { asume la } \\
\text { responsabilidad } \\
\text { de los mismos }\end{array}$ & 16.7 & 28.9 & 33.3 & 53.0 & 50.0 & 13.3 & - & 3.6 & - & 1.2 & 4.00 & 3.67 \\
\hline $\begin{array}{l}\text { Los docentes } \\
\text { toman acciones } \\
\text { correctivas en } \\
\text { respuesta a } \\
\text { los problemas } \\
\text { generados por } \\
\text { su actuación. }\end{array}$ & 16.7 & 33.7 & 16.7 & 49.4 & 66.7 & 13.3 & - & 3.6 & - & - & 3.50 & 4.13 \\
\hline (\%) Indicador & 22.2 & 36.9 & 16.7 & 47.8 & 55.5 & 12.1 & 5.6 & 2.4 & - & 0.8 & & \\
\hline \multicolumn{11}{|c|}{ Media del indicador. Rectores/ Docentes } & 3.56 & 4.18 \\
\hline
\end{tabular}

Fuente: Elaboración propia a partir de los datos obtenidos del instrumento

Observando la segunda y tercera aseveración, presentada en la tabla 7, se evidencia las respuestas de los rectores enmarcadas en la posición neutral, donde el 50\% afirmó que algunas veces cuando el personal comete errores, asume la responsabilidad de los mismos y para el $66,7 \%$ algunas veces los docentes toman acciones correctivas en respuesta a los problemas generados por su actuación. Opiniones, bastante preocupantes, en el sentido que el valor de la responsabilidad, según los rectores, está relativamente ausente en la actuación del personal docente.

Sin embargo, y como era de esperarse, los docentes exhiben respuestas contrarias a los rectores. Para ellos, casi siempre (53\%) y siempre $(28,9 \%)$ asumen la responsabilidad de sus errores; de igual manera, piensan que casi siempre $(49,4 \%)$ y siempre $(33,7 \%)$ toman acciones correctivas cuando se requiere enmendar algún problema generado por ellos.

Los resultados anteriores permiten comentar que para Vegas y col (2006), la responsabilidad es el sentimiento de los miembros de la organización acerca de su autonomía en la toma de decisiones relacionadas a su trabajo. Es el considerarse ser su propio jefe y no tener doble chequeo en el trabajo. Una primera condición que facilita desarrollar la responsabilidad de los miembros de la comunidad académica escolar, es asegurar el conocimiento que cada uno de ellos tienen de la institución, de cuáles son sus tareas y qué se espera de su actuación. 
Con este indicador se busca que los docentes entiendan cuál puede ser su aporte para mejora de la calidad institucional, facilitándoles medios para controlar y gestionar los procesos en que participan dentro de su ámbito de responsabilidad. La dirección debe, diseñar procedimientos cuya implantación apoye la asunción de la participación y responsabilidad como elemento de la cultura de la institución.

El indicador Recompensa, se detalla en la tabla 8, donde se debe puntualizar que la mayor parte de los rectores y docentes coincidieron en opinar negativamente sobre las tres aseveraciones presentadas. Nótese como para los rectores casi nunca $(33,3 \%)$ y nunca $(16,7 \%)$ se ofrecen incentivo a los docentes, solo un 33,3\% señaló que algunas veces se daban incentivos. Igual porcentaje a los anteriores señaló que nunca y casi nunca se reconoce la buena labor del personal docente y el $83,3 \%$ fue enfático al indicar que nunca se ofrecen incentivos adicionales a los establecidos en el contrato de trabajo.

Frente a estos resultados, en la tabla 8 se observa como la mayoría del personal docente está de acuerdo a la opinión de los rectores. Para un grupo importante de ellos nunca $(26,5 \%)$ y casi nunca $(22,9 \%)$ se les ofrece incentivos por su desempeño laboral. Según ellos, y un tanto contrario a la opinión de los rectores, algunas veces $(28,9 \%)$, casi siempre $(24,1 \%)$, nunca $(22,9 \%)$ y casi nunca $(15,7 \%)$, se les reconoce su buena labor. En tanto que otros señalaron, que nunca $(37,3 \%)$, algunas veces $(28,9 \%)$ y casi nunca $(18,1 \%)$, se ofrecen incentivos adicionales a los establecidos en el contrato de trabajo.

Tabla 8. Recompensa

\begin{tabular}{|c|c|c|c|c|c|c|c|c|c|c|c|c|}
\hline \multirow{4}{*}{$\begin{array}{l}\text { Muestra } \\
\text { Aseveraciones }\end{array}$} & \multicolumn{10}{|c|}{ Alternativas de respuestas } & \multirow{2}{*}{\multicolumn{2}{|c|}{$\begin{array}{c}\text { Media } \\
\text { aseveración }\end{array}$}} \\
\hline & \multicolumn{2}{|c|}{ Siempre } & \multicolumn{2}{|c|}{ Casi Siempre } & \multicolumn{2}{|c|}{ Algunas veces } & \multicolumn{2}{|c|}{ Casi nunca } & \multicolumn{2}{|c|}{ Nunca } & & \\
\hline & Rector & Doc. & Rector & Doc. & Rector & Doc. & Rector & Doc. & Rector & Doc. & \multirow{2}{*}{ Rector } & \multirow{2}{*}{ Doc } \\
\hline & $\%$ & $\%$ & $\%$ & $\%$ & $\%$ & $\%$ & $\%$ & $\%$ & $\%$ & $\%$ & & \\
\hline $\begin{array}{c}\text { Ofrecen } \\
\text { incentivos a } \\
\text { los docentes } \\
\text { de acuerdo al } \\
\text { desempeño } \\
\text { laboral } \\
\end{array}$ & - & 6.0 & 16.7 & 13.3 & 33.3 & 31.3 & 33.3 & 22.9 & 16.7 & 26.5 & 2.50 & 2.49 \\
\hline $\begin{array}{l}\text { Hay un } \\
\text { sistema de } \\
\text { reconocimiento } \\
\text { por la buena } \\
\text { labor del } \\
\text { personal docente }\end{array}$ & 16.7 & 8.4 & - & 24.1 & 33.3 & 28.9 & 33.3 & 15.7 & 16.7 & 22.9 & 2.67 & 2.80 \\
\hline $\begin{array}{c}\text { Se ofrecen } \\
\text { incentivos } \\
\text { adicionales a los } \\
\text { establecidos en } \\
\text { el contrato de } \\
\text { trabajo }\end{array}$ & - & 3.6 & - & 12.0 & 16.7 & 28.9 & - & 18.1 & 83.3 & 37.3 & 1.33 & 2.27 \\
\hline (\%) Indicador & 5.6 & 6.0 & 5.6 & 16.5 & 27.7 & 29.7 & 22.2 & 18.9 & 38.9 & 28.9 & & \\
\hline Media del indic & $R e$ & es/ & entes & & & & & & & & 2.17 & 2.52 \\
\hline
\end{tabular}

Fuente: Elaboración propia a partir de los datos obtenidos del instrumento 
Para Chiavenato (2006) la recompensa, corresponde a la percepción de los miembros de la institución sobre la adecuación de los premios recibidos por el trabajo bien hecho. Se refiere al sentimiento que los individuos tienen acerca de la importancia del estímulo recibido de la dirección que se manifiesta como componentes del sistema de recompensas.

Estos resultados se contradicen con lo expresado por Bohlander y Snell (2008), quienes aseguran que, al vincular los incentivos con los resultados, los trabajadores aplicarán cada vez más sus habilidades y conocimientos en sus puestos de trabajo, sintiéndose motivados a trabajar en equipo. El desempeño laboral viene dado por factores motivacionales los cuales incrementan la productividad, al lograr que los trabajadores ejecuten sus labores con toda su capacidad.

En cuanto a Riesgo, se puede decir que esta categoría se relaciona al sentimiento de reto personal y de toma de riesgo corporativo, asociado con el éxito de la organización. Así, en la tabla 14 , se observa como la mayoría de los rectores piensan que casi siempre (50\%) y siempre $(16,7 \%)$ se han tomado riesgos en los momentos oportunos, para enfrentar una situación inesperada, el resto opinó dentro de las alternativas negativas.

Por otra parte, se muestran opiniones extremas en las respuestas dadas por los rectores a la segunda aseveración. Para el 33,3\% casi siempre y para el mismo porcentaje, casi nunca se asumen riesgos para adaptarse a las necesidades del entorno social. En tanto, el 50\% señaló que algunas veces cuando hay un reto para la institución, todo el personal participa activamente en la respuesta al mismo. Mientras que para el 33,3\% de los rectores siempre todo el personal participa para enfrentar los retos presentados.

Tabla 9. Riesgo

\begin{tabular}{|c|c|c|c|c|c|c|c|c|c|c|c|c|}
\hline \multirow{4}{*}{ Aseveraciones } & \multicolumn{10}{|c|}{ Alternativas de respuestas } & \multirow{2}{*}{\multicolumn{2}{|c|}{$\begin{array}{l}\text { Media } \\
\text { aseveración }\end{array}$}} \\
\hline & \multicolumn{2}{|c|}{ Siempre } & \multicolumn{2}{|c|}{ Casi Siempre } & \multicolumn{2}{|c|}{ Algunas veces } & \multicolumn{2}{|c|}{ Casi nunca } & \multicolumn{2}{|c|}{ Nunca } & & \\
\hline & Rector & Doc. & Rector & Doc. & Rector & Doc. & Rector & Doc. & Rector & Doc. & \multirow{2}{*}{ Rector } & \multirow{2}{*}{ Doc. } \\
\hline & $\%$ & $\%$ & $\%$ & $\%$ & $\%$ & $\%$ & $\%$ & $\%$ & $\%$ & $\%$ & & \\
\hline $\begin{array}{l}\text { Se han tomado } \\
\text { riesgos en los } \\
\text { momentos oportunos, } \\
\text { para enfrentar una } \\
\text { situación inesperada }\end{array}$ & 16.7 & 9.6 & 50.0 & 43.4 & - & 20.5 & 16.7 & 16.9 & 16.6 & 9.6 & 3.33 & 3.27 \\
\hline $\begin{array}{l}\text { Se asumen riesgos } \\
\text { para adaptarse a } \\
\text { las necesidades del } \\
\text { entorno social. }\end{array}$ & 16.7 & 12.0 & 33.3 & 44.6 & 16.7 & 25.3 & 33.3 & 10.9 & - & 7.2 & 3.33 & 3.43 \\
\hline $\begin{array}{c}\text { Cuando hay un reto } \\
\text { para la institución, } \\
\text { todo el personal } \\
\text { participa activamente } \\
\text { en la respuesta al } \\
\text { mismo }\end{array}$ & 33.3 & 25.3 & 16.7 & 49.4 & 50.0 & 21.7 & - & 3.6 & - & - & 3.83 & 3.96 \\
\hline (\%) Indicador & 22.2 & 15.6 & 33.3 & 45.8 & 22.2 & 22.5 & 16.7 & 10.5 & 5.6 & 5.6 & & \\
\hline \multicolumn{11}{|c|}{ Media del indicador. Rectores/ Docentes } & 3.49 & 3.55 \\
\hline
\end{tabular}

Fuente: Elaboración propia a partir de los datos obtenidos del instrumento 
Continuando con la descripción del indicador en la tabla 9 se explicitan las respuestas de los docentes, quienes en su mayoría piensan que casi siempre $(43,4 \%)$ y algunas veces $(20,5 \%)$ en la institución se han tomado riesgos en los momentos oportunos, para enfrentar una situación inesperada. De igual manera, el $44,6 \%$ y el $12 \%$ indicó que casi siempre y siempre respectivamente en las instituciones abordadas se asumen riesgos para adaptarse a las necesidades del entorno social. Comportamiento similar adoptaron las respuestas dadas para la tercera aseveración, donde casi siempre $(49,4 \%)$ y siempre $(25,3 \%)$ los docentes aseveran que cuando hay un reto para la institución, todo el personal participa activamente en la respuesta al mismo.

La situación presentada en las instituciones educativas abordadas, con respecto al indicador: calor y apoyo, se puede observar en detalle en la tabla 10, donde se presentan respuestas divididas entre las diferentes alternativas, sin embargo, la mayoría de los rectores (siempre 33,3\% y casi siempre 33,3\%) piensan que en la institución prevalece un ambiente cordial entre los miembros de la organización, el resto opinó que algunas veces $(16,9 \%)$ o casi nunca (16,9\%) esto es así. Mientras que el $47 \%$ de los docentes argumentó que casi siempre, el $33,7 \%$ siempre, el $16,9 \%$ que algunas veces y el $2,4 \%$ prevalece la cordialidad entre todos los integrantes que conforman la institución escolar.

En el mismo orden de ideas, la mitad de la muestra de rectores señaló que algunas veces, siempre $(33,3 \%)$ y casi siempre $(16,7 \%)$ prevalece el trabajo en equipo para mejorar el desempeño institucional. En tanto, para solo el $43,4 \%$ los docentes casi siempre y $36,1 \%$ siempre, el resto indicó algunas veces $(19,3 \%)$ y casi nunca $(1,2 \%)$, el trabajo en equipo mejora el desempeño institucional.

Tabla 10. Calor y apoyo

\begin{tabular}{|c|c|c|c|c|c|c|c|c|c|c|c|c|}
\hline \multirow{4}{*}{$\begin{array}{l}\text { Muestra } \\
\text { Aseveraciones }\end{array}$} & \multicolumn{10}{|c|}{ Alternativas de respuestas } & \multirow{2}{*}{\multicolumn{2}{|c|}{$\begin{array}{c}\text { Media } \\
\text { aseveración }\end{array}$}} \\
\hline & \multicolumn{2}{|c|}{ Siempre } & \multicolumn{2}{|c|}{ Casi Siempre } & \multicolumn{2}{|c|}{ Algunas veces } & \multicolumn{2}{|c|}{ Casi nunca } & \multicolumn{2}{|c|}{ Nunca } & & \\
\hline & Rector & Doc. & Rector & Doc. & Rector & Doc. & Rector & Doc. & Rector & Doc. & \multirow{2}{*}{ Rector } & \multirow{2}{*}{ Doc. } \\
\hline & $\%$ & $\%$ & $\%$ & $\%$ & $\%$ & $\%$ & $\%$ & $\%$ & $\%$ & $\%$ & & \\
\hline $\begin{array}{c}\text { Prevalece un } \\
\text { ambiente cordial } \\
\text { entre los miembros } \\
\text { de la institución }\end{array}$ & 33.3 & 33.7 & 33.3 & 47.0 & 16.7 & 16.9 & 16.7 & 2.4 & - & - & 3.83 & 4.12 \\
\hline $\begin{array}{c}\text { Prevalece el } \\
\text { trabajo en equipo } \\
\text { para mejorar } \\
\text { el desempeño } \\
\text { institucional } \\
\end{array}$ & 33.3 & 36.1 & 16.7 & 43.4 & 50.0 & 19.3 & - & 1.2 & - & - & 3.83 & 4.14 \\
\hline $\begin{array}{l}\text { Las iniciativas } \\
\text { académicas } \\
\text { tomadas por el } \\
\text { personal docente, } \\
\text { reciben apoyo de } \\
\text { los directivos. }\end{array}$ & 50.0 & 24.1 & 50.0 & 57.8 & - & 14.5 & - & 3.6 & - & - & 4.50 & 4.02 \\
\hline (\%) Indicador & 38.9 & 31.3 & 33.3 & 49.4 & 22.2 & 16.9 & 5.6 & 2.4 & 38.9 & 28.9 & & \\
\hline \multicolumn{11}{|c|}{ Media del indicador. Rectores/ Docentes } & 4.05 & 4.09 \\
\hline
\end{tabular}

Fuente: Elaboración propia a partir de los datos obtenidos del instrumento. 
Para la tercera aseveración, todos los rectores manifestaron una posición positiva con la misma (siempre 50\% y casi siempre 50\%). De igual manera, más de la mitad de la muestra de docentes piensan que casi siempre $(57,8 \%)$ y siempre $(24,1 \%)$ las iniciativas académicas tomadas por el personal docente, reciben apoyo de los directivos.

Para Chiavenato (2006) el calor y apoyo es la percepción por parte de los miembros de la organización acerca de la existencia de un ambiente de trabajo grato y de buenas relaciones sociales tanto entre pares como entre jefes y subordinados. De acuerdo a Ortiz y col (2010) es el sentimiento de los miembros de la organización sobre la existencia de un espíritu de ayuda de parte de los directivos y de otros empleados del grupo. De manera que esta dimensión orienta a la promoción del trabajo en equipo y la capacidad de compartir habilidades entre todos.

El último indicador planteado esta referido al abordaje del conflicto; en este sentido para Funes (2000) los conflictos pueden originarse por la percepción de divergencia de necesidades o intereses que no satisfacen simultáneamente o de forma conjunta, debido a las incompatibilidades o diferencia en los valores o en la definición de la situación, también por competencia o escasez de recursos. Sin embargo, un ambiente donde surjan conflictos puede ser una oportunidad, donde la motivación y la comunicación permiten poner en evidencia las competencias del personal, estimulando la diversidad de opiniones en beneficio de la institución educativa.

Tabla 11. Conflicto

\begin{tabular}{|c|c|c|c|c|c|c|c|c|c|c|c|c|}
\hline \multirow{4}{*}{ Aseveraciones } & \multicolumn{10}{|c|}{ Alternativas de respuestas } & \multirow{2}{*}{\multicolumn{2}{|c|}{$\begin{array}{l}\text { Media } \\
\text { aseveración }\end{array}$}} \\
\hline & \multicolumn{2}{|c|}{ Siempre } & \multicolumn{2}{|c|}{ Casi Siempre } & \multicolumn{2}{|c|}{ Algunas veces } & \multicolumn{2}{|c|}{ Casi nunca } & \multicolumn{2}{|c|}{ Nunca } & & \\
\hline & Rector & Doc. & Rector & Doc. & Rector & Doc. & Rector & Doc. & Rector & Doc. & \multirow{2}{*}{ Rector } & \multirow{2}{*}{ Doc. } \\
\hline & $\%$ & $\%$ & $\%$ & $\%$ & $\%$ & $\%$ & $\%$ & $\%$ & $\%$ & $\%$ & & \\
\hline $\begin{array}{c}\text { Se incentiva la } \\
\text { discusión sobre } \\
\text { los aspectos } \\
\text { relacionados } \\
\text { al quehacer } \\
\text { institucional }\end{array}$ & 16.7 & 22.9 & 50.0 & 48.2 & 33.3 & 16.9 & - & 7.2 & - & 4.8 & 3.83 & 3.77 \\
\hline $\begin{array}{c}\text { Se estimula la } \\
\text { participación de } \\
\text { todo el personal en } \\
\text { las actividades de } \\
\text { la institución, aun } \\
\text { y cuando existan } \\
\text { manifiestos } \\
\text { desacuerdos entre } \\
\text { ellos }\end{array}$ & 33.3 & 24.1 & 33.3 & 43.4 & 16.7 & 24.1 & - & 7.2 & 16.7 & 1.2 & 3.83 & 3.82 \\
\hline $\begin{array}{l}\text { Utiliza el consenso } \\
\text { para llegar a } \\
\text { acuerdos en } \\
\text { situaciones de } \\
\text { conflicto } \\
\end{array}$ & 50.0 & 26.5 & 33.3 & 50.6 & 16.7 & 18.1 & - & 3.6 & - & 1.2 & 4.33 & 3.98 \\
\hline$(\%)$ Indicador & 33.3 & 24.5 & 38.9 & 47.4 & 22.2 & 19.7 & - & 6.0 & 5.6 & 2.4 & & \\
\hline Media del indicado & r. Rector & es/ Do & entes & & & & & & & & 3.99 & 3.86 \\
\hline
\end{tabular}

Fuente: Elaboración propia a partir de los datos obtenidos del instrumento. 
De manera que en la tabla 11 , en cuanto a la primera aseveración los rectores manifestaron que casi siempre (50\%) algunas veces $(33,3 \%)$ y siempre $(16,7 \%)$ se incentiva la discusión sobre los aspectos relacionados al quehacer institucional. Al observar las respuestas de los docentes, el 48,2\% precisó como casi siempre y el 22,9\% indicó que siempre se incentivas discusiones que redundan en beneficio institucional. Solo un 16,9\% asumió una posición neutral y el resto mantuvo una opinión negativa con respecto a la aseveración presentada.

Por otra parte, la muestra de los rectores encuestados manifestaron posiciones diversas al indicar con las alternativas siempre (33,3\%), casi siempre (33,3\%), algunas veces $(16,7 \%)$ y casi nunca $(16,7 \%)$ se estimula la participación de todo el personal en las actividades de la institución, aun y cuando existan manifiestos desacuerdos entre ellos. En contraposición un $43,4 \%$ de los docentes opinó casi siempre, un $24,1 \%$ siempre y el mismo porcentaje piensa que algunas veces se estimula la participación de ellos, aún y cuando haya desacuerdo de opiniones.

Cerrando la discusión de este indicador, se tiene apreciaciones positivas, tanto de los rectores como del personal docente entrevistado con respecto a sí en la institución se utiliza el consenso para llegar a acuerdos en situaciones de conflicto. Así, más del 50\% de los rectores y más del $50 \%$ de los docentes coincidieron en afirmar que siempre y casi siempre se recurre al consenso entre ambos para resolver las situaciones conflictivas que se presentan en el quehacer académico.

Observando la tabla 12, se aprecia la media para los seis indicadores seleccionados, donde los valores de la media aritmética obtenidos para el grupo de rectores (3.50) fueron inferiores a la obtenida en las respuestas dadas por los docentes (3.74), enmarcándose estos valores en el rango de medianamente apropiados, con una probable tendencia a inapropiados por estar ubicados en el rango inferior del valor.

Tabla 12. Resumen: Tipos de clima organizacional

\begin{tabular}{|c|c|c|}
\hline Tipos de climas & Rectores & Personal Docente \\
\hline Estructura organizacional & 3.72 & 4.25 \\
\hline Responsabilidad & 3.56 & 4.18 \\
\hline Recompensa & 2.17 & 2.52 \\
\hline Riesgo & 3.49 & 3.55 \\
\hline Calor y apoyo & 4.05 & 4.09 \\
\hline Conflicto & 3.99 & 3.86 \\
\hline Media & 3.50 & 3.74 \\
\hline
\end{tabular}

Fuente: Elaboración propia

En detalle, se presentan los bajos valores del promedio del indicador Recompensa, lo cual indica que este tipo de categoría no es una dimensión que está presente en el clima organizacional de las instituciones abordadas, ubicándose dentro de la tendencia inapropiada, 
según el baremo diseñado para tal fin. En contraposición el que alcanzó un mayor valor fue el indicador calor y apoyo tanto para los rectores (4.05) como para los docentes (4.09).

Se observa, además, que el resto de los indicadores: estructura organizacional, responsabilidad, calor y apoyo, conflicto y riesgo muestran una la clara tendencia de los valores en ubicarse en un rango de medianamente apropiado, donde el mayor valor estuvo representado, en un grupo importante, por las respuestas dadas por los docentes.

En la tabla 13, se observan las respuestas dadas por la muestra de rectores y docentes en referencia a variable clima organizacional. Así, la alternativa algunas veces exhibe el mayor porcentaje $(31,1 \%)$ para el grupo de rectores; mientras que para los docentes la mayor cantidad de respuestas estuvo orientada hacia la alternativa casi siempre (36,2\%). Nótese también, como la media para ambos grupos de informantes fue similar.

Tabla 11. Conflicto

\begin{tabular}{|c|c|c|c|c|c|c|c|c|c|c|c|c|}
\hline Muestra & & & Rectores & & & & & Docentes & & & $\mathrm{Me}$ & \\
\hline $\begin{array}{l}\text { Alternativas } \\
\text { Dimensiones }\end{array}$ & $\underset{\%}{\text { Siempre }}$ & $\begin{array}{l}\text { Casi } \\
\underset{\%}{\text { siempre }}\end{array}$ & $\begin{array}{l}\text { Algunas } \\
\text { veces } \\
\%\end{array}$ & $\begin{array}{l}\text { Casi } \\
\text { nunca } \\
\%\end{array}$ & $\underset{\%}{\text { Nunca }}$ & $\underset{\%}{\text { Siempre }}$ & $\begin{array}{c}\text { Casi } \\
\text { siempre } \\
\%\end{array}$ & $\begin{array}{c}\text { Algunas } \\
\text { veces } \\
\%\end{array}$ & $\begin{array}{l}\text { Casi } \\
\text { nunca } \\
\%\end{array}$ & $\underset{\%}{\text { Nunca }}$ & Rector & Doc. \\
\hline $\begin{array}{l}\text { Tipos de clima } \\
\text { organizacional }\end{array}$ & 33.3 & 23.3 & 30.9 & 8.4 & 4.1 & 22.6 & 32.4 & 25.1 & 12.0 & 7.9 & 3.71 & 3.50 \\
\hline $\begin{array}{l}\text { Dimensiones } \\
\text { del clima } \\
\text { organizacional }\end{array}$ & 24.1 & 26.8 & 31.4 & 9.3 & 8.4 & 25.3 & 40.0 & 21.0 & 7.2 & 6.5 & 3.50 & 3.74 \\
\hline$\%$ Variable & 28.7 & 25.1 & 31.1 & 8.9 & 6.2 & 23.9 & 36.2 & 23.1 & 9.6 & 7.2 & & \\
\hline Media de la var & iable. $R e$ & ores/ Do & ntes & & & & & & & & 3.61 & 3.62 \\
\hline
\end{tabular}

Fuente: Elaboración propia a partir de los datos obtenidos del instrumento.

\section{CONCLUSIONES}

De acuerdo a los planteamientos expresados en los párrafos anteriores, se puede concluir que el clima organizacional en las instituciones educativas abordadas, se ubicó en un rango medianamente apropiado.

Los resultados permitieron señalar que en las instituciones a nivel de educación básica primaria públicas, ubicadas la comuna 7 , de la localidad 3 se está en presencia de una conjunción de diversos tipos de clima organizacional, evidenciándose un tipo de clima caracterizado como autoritario paternalista, donde se motiva al docente a través de recompensas, las normas institucionales están establecidas solo para guiar el comportamiento del personal docente y administrativo y solo algunas veces o casi nunca la comunicación con los docentes es para discutir la labor diaria en la institución. 
Pero también hay un predominio del tipo de clima participativo consultivo, donde se observa a un personal directivo que genera un ambiente de trabajo basado en la confianza y el respeto mutuo entre el personal; ofrece incentivos a las ideas y opiniones de los docentes relacionadas al buen funcionamiento institucional y se propicia un ambiente de trabajo donde el docente se siente coparticipe del funcionamiento de la misma.

Lo antes descrito permite recomendar mejorar el clima en el ambiente laboral, minimizando el tipo autoritario paternalista y reforzando el participativo en grupo y consultivo. Para esto se requiere incentivar las ideas y opiniones de los docentes relacionadas al buen funcionamiento institucional y permitirles a los docentes discutir con los rectores los problemas relacionados al trabajo diario.

En cuanto a Identificar las dimensiones del clima organizacional en las instituciones escolares en Santa Marta, Colombia, se reflejan resultados con tendencia positiva para los seis indicadores: Estructura organizacional, responsabilidad, recompensa, riesgo, calor y apoyo y conflicto. Se observa que la media aritmética para los seis indicadores obtenidos para el grupo de rectores (3.50) alcanzó un valor menor a la media de los docentes (3.74), ubicándose éstos en el rango de medianamente apropiados, con una probable tendencia a inapropiados por estar cercanos al rango inferior del valor. Se debe puntualizar que el indicador Recompensa fue el que alcanzó la menor ponderación ubicándose dentro de la tendencia inapropiada, lo cual indica que este tipo de categoría no está presente en el clima organizacional de las instituciones abordadas, mientras que el indicador que alcanzó un mayor promedio fue calor y apoyo.

En ese sentido se recomienda motivar al docente para que se comprometa con su aporte, en mejoramiento de la calidad institucional, para lo cual el rector debe diseñar procedimientos cuya implantación apoye la participación y responsabilidad como elemento de la cultura de la institución.

Por otra parte, se sugiere a los rectores potenciar la motivación de los docentes a través de un sistema de reconocimiento que incorporen explícitamente recompensas al esfuerzo individual y a los resultados colectivos. Asimismo, desarrollar sistemas eficaces de administración del desempeño, premios y reconocimientos para apoyar el trabajo de alto desempeño. 


\section{REFERENCIAS BIBLIOGRÁFICAS}

- Brunet, L (2008). El clima de trabajo en las organizaciones. Definición, diagnóstico y consecuencias. México. Editorial Trillas.

- Bohlander, G, Snell S. (2008). Administración de recursos humanos. México. Editorial CenegeLearning Latino América.

- Chiavenato, I. (2002). Administración, Teoría Procesos y Práctica. 3a Ed. México. Editorial Mc Graw Hill.

- Chiavenato, I. (2006). Introducción a la Teoría General de la Administración. $7^{\mathrm{a}}$ Edicion. México. Editorial Mc Graw Hill.

- Chiavenato, I. (2011). Administración de Recursos Humanos. El Capital Humano de las organizaciones. México. Editorial Mc Graw Hill.

- Daft, R. y Marcic, D. (2006). Introducción a la Administración. Cuarta Edición. México. Editorial Thomson.

- Davis K. y Newstrom J. (2004), Comportamiento Humano en el Trabajo. 10ma. Edición). México. Editorial Thomson

- Funes L. S. (2000). Resolución de conflictos en la escuela: Una herramienta para la cultura de la paz y la convivencia. En Revista Contextos Educativos. Vol 3. Pp 91-106. Universidad de la Rioja, España.

- García, M. (2009). Clima Organizacional y su Diagnóstico: Una aproximación Conceptual. En Revista Cuadernos de Administración Vol. 25, N. 42. JulioDiciembre. Universidad del Valle, Cali, Colombia. Disponible en: http://www. redalyc.org/articulo.oa?id=225014900004

- Gibson, J.; Ivancevich, J.; Donnelly, J. (2006). Organizaciones. Duodécima Edición. México.

- Gómez R. C. A (2004). Diseño, construcción y validación de un instrumento que evalúa clima organizacional en empresas colombianas, desde la teoría de respuesta al ITEM. Acta Colombiana de Psicología, núm. 11, pp. 97-113 Universidad Católica de Colombia Bogotá, Colombia . Disponible en: http://www.redalyc.org/articulo. oa? id=79801108. Fecha de consulta 23/05/2017

- Goncalves, A.. (2007). Dimensiones del clima organizacional. Sociedad Latinoamericana para el aprendizaje. Disponible en: http://www.educadormarista. com/proyectoaprender/climaoganizacional.htmtiva Consultado: mayo 2017

- Hitt, M.; Black, S. y Porter, L. (2006). Administración. Novena edición. México. Pearson Educación.

- Jones, G. y George, J. (2006). Administración Contemporánea. México. Editorial McGraw-Hill.

- Koontz, H, Weihrich, H. y Cannice, M. (2012). Administración una perspectiva global y empresarial. Edición 14. México. McGraw-Hill, Interamericana. Editores.

- Litwin, G.. y Stinger, R. (1968). The influence of organizational climate on human motivation. Michigan: Foundation for Research on Human Behavior, nd. 
- Ojeda, J. (2014).Clima organizacional en instituciones de educación primaria. Revista CICAG Vol. 11 N². http://publicaciones.urbe.edu/index.php/cicag/issue/ view/304

- Olaz Á. (2010). Propuesta de un modelo de medición multivariable del clima laboral en organizaciones complejas. Un enfoque metodológico Departamento de Sociología y Política Social Facultad de Economía y Empresa. Universidad de Murcia

- Ortiz P., Olaz A. y Carrasco, A. (2009) Clima y cultura en la empresa familiar, en J. Monreal, G. Sánchez, A. Meroño y R. Sabater (coords.), La Gestión de las Empresas Familiares, Madrid, Thomson Reuters, pp. 379-394.

- Tapia, J. (2007). Introducción al Análisis de Datos con SPSS para Windows. Venezuela. Ediciones Universidad Ezequiel Zamora.

- UNESCO (2009). Tras la pista de una revolución académica: Informe sobre las tendencias actuales para la Conferencia Mundial sobre la Educación Superior. Francia. Recuperado de http://unesdoc.unesco.org.

- Vega, D., Arévalo A., Sandoval J., Aguilar M., y Giraldo J. (2006) Panorama sobre los estudios de clima organizacional en Bogotá, Colombia (1994-2005). Revista Diversitas - Perspectivas en Psicología - Vol. 2, No. 2, Págs. 329 -349. 